\title{
NEOCLASSICAL CONDUCTIVITY
}

OF A TOKAMAK PLASMA

BY

S, P, HIRSHMAN, R, J, HAWRYLUK AND

B , BIRGE

\section{PLASMA PHYSICS LABORATORY}

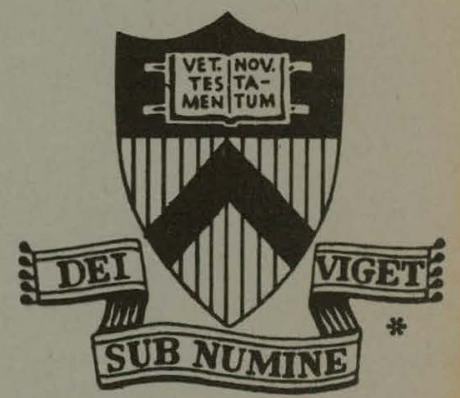

DISTERUTION OF THLS DUCUMENT IS UNEIATTEO

\section{PRINCETON \\ UNIVERSITY PRINCETON, NEW JERSEY}

This work was supported by U. S. Energy Research and Development Administration Contract $\mathrm{E}(11-1)-3073$. Reproduction, translation, publication, use and disposal, in whole or in part, by or for the United States Government is permitted. 


\section{DISCLAIMER}

This report was prepared as an account of work sponsored by an agency of the United States Government. Neither the United States Government nor any agency Thereof, nor any of their employees, makes any warranty, express or implied, or assumes any legal liability or responsibility for the accuracy, completeness, or usefulness of any information, apparatus, product, or process disclosed, or represents that its use would not infringe privately owned rights. Reference herein to any specific commercial product, process, or service by trade name, trademark, manufacturer, or otherwise does not necessarily constitute or imply its endorsement, recommendation, or favoring by the United States Government or any agency thereof. The views and opinions of authors expressed herein do not necessarily state or reflect those of the United States Government or any agency thereof. 


\section{DISCLAIMER}

Portions of this document may be illegible in electronic image products. Images are produced from the best available original document. 
NOTICE

This report was prepared as an account of work sponsored by the United States Government. Neither the United States nor the United States Energy Research and Development Administration, nor any of their employees, nor any of their contractors, subcontractors, or their employees, makes any warranty, express or implied, or assumes any legal liability or responsibility for the accuracy, completeness or usefulness of any information, apparatus, product or process disclosed, or represents that its use would not infringe privately owned rights.

Printed in the United States of America.

Available from

National Technical Information Service

U. S. Department of Commerce 5285 Port Royal Road

Springfield, Virginia 22151

Price: Printed Copy \$_*; Microfiche $\$ 3.00$

*Pages

$$
1-50
$$

$51-150$

$151-325$

$326-500$

501-1000
NTIS

Selling Price

$\$ 4.00$

5.45

7.60

10.60

13.60 
Neoclassical Conductivity of a Tokamak Plasma

S. P. Hirshman, R. J. Hawryluk, and B. Birge

Plasma Physics Laboratory

Princeton University

Princeton, New Jersey

08540

February 1977

PPPL-1326 
Neoclassical Conductivity of a Tokamak Plasma

by

S. P. Hirshman, R. J. Hawryluk and B.o Birge

Plasma Physics Laboratory

Princeton University

Princeton, New Jersey 08540

\begin{abstract}
The parallel neoclassical conductivity of a fully ionized tokamak plasma is determined for all values of the effective charge and electron collisionality parameter and for arbitrary aspect ratios. A simple analytic expression for the conductivity is obtained and shown to agree accurately with numerical results over a wide range of discharge parameters.
\end{abstract}




\section{FORMULATION}

An accurate calculation of the neoclassical parallel conductivity $\sigma_{\|}$is essential for obtaining an estimate of the effective charge

$$
\bar{z}=\sum_{i \neq e} n_{i} z_{i}^{2} / n_{e}
$$

and hence, the impurity content of a tokamak plasma [1]. Previous calculations of $\sigma_{\|}$have been deficient in several respects. In some calculations $[2,3], \sigma_{\|}$is tabulated only for certain integral values of $\bar{z}$, whereas non-integral $\bar{z}$ are clearly relevant in a multispecies plasma. Rutherford and Düchs [4] have given a formula for $\sigma \|$, which incorrectly neglects the $\overline{\mathrm{z}}$ dependence of the trapping correction, arising from collisions between trapped and circulating. electrons, and gives an inaccurate dependence on $\bar{z}$ of the electron collisionality parameter. Finally, the tabulated calculations of Hinton and Hazeltine [3] are restricted to very small values of the inverse aspect ratio

$$
\delta=r / R_{0}
$$

To generalize and improve these previous values for the conductivity, we have integrated numerically an expression for $\sigma \|$, derived by Hirshman and isigmar [5], which is valid for all $\bar{z}$ and throughout the three neoclassical regimes. Furthermore, 
straightforward application of the method discussed in Refs. $[6,7]$ extends the present result for $\sigma\|\|_{\text {to }}$ include finite aspect ratio effects, (which are most significant in the lowcollision frequency regime).

The neoclassical conductivity relates the parallel current density to the electric field averaged over a magnetic flux surface:

$$
\mathrm{j}_{\|}=\sigma_{\|}<\underset{\sim}{\mathrm{E}} \cdot \mathrm{B}>\mathrm{B} /\left\langle\mathrm{B}^{2}>\right.
$$

where $\langle A\rangle$ denotes the flux surface average of $A$. Following Refs. $[5,7], \sigma \|$ may be expressed in terms of the classical Spitzer function $F_{s}\left(\bar{z}, x_{e}\right)$, where $x_{e}=v / \alpha_{e}$ and $\alpha_{e}^{2}=2 T_{e} / m_{e}$, as follows:

$$
\sigma_{\|} / \sigma_{0}=\frac{8}{3 \sqrt{2}} \int_{0}^{\infty} x_{e}^{4} e^{-x_{e}^{2}} d x_{e}\left(\left(1-f_{T}^{*}\right) F_{S}\left[1-f_{T}^{*}\left(\nu_{D}^{e} \tau_{e} e_{S}^{F}-1\right)\right]\right) .
$$

Here, $\sigma_{o}=n_{e} e^{2} \tau_{e e} / m_{e} ; \tau_{e e}=3 m_{e}^{2} \alpha_{e}^{3} /\left(16 \sqrt{\pi} n e^{\left.e^{4} \ln \Lambda\right)}\right.$ is the electron Braginskii time,

$$
\begin{aligned}
\nu_{D}^{e}\left(x_{e}\right) & =\nu_{D}^{e e}+\sum_{i \neq e} \nu_{D}^{e i} \\
& =\left(\frac{4}{3 \sqrt{\pi}} \tau_{\text {ee }}\right)^{-1}\left(\frac{\Phi\left(x_{e}\right)-G\left(x_{e}\right)+\bar{z}}{x_{e}^{3}}\right)
\end{aligned}
$$

is the total pitch angle diffusion frequency ( $\Phi$ and $G$ are the error function and Chandrasekhar function, respectively), and 


$$
f_{T}^{*}\left(x_{e}\right)=f_{T}\left(1+1.75 v_{*}^{*}\left[\nu_{D}^{e}\left(x_{e}\right) \tau_{e e}\right] x_{e}^{-1}\right)^{-1}
$$

is the effective trapped fraction as a function of electron energy $T_{e} \dot{x}_{e}^{2}$. In Eq. (6),

$$
v_{*_{e}}=\sqrt{2} \delta^{-3 / 2} \frac{R_{o} q}{\alpha_{e}} \tau_{e e}^{-1}
$$

is the electron collisionality parameter (chosen independent of $z)$, where $q=r_{T} /\left(R_{Q} B_{p}\right)$ is the safety factor, and $f_{T}$ is the fraction of trapped particles in the banana regime $\left(v_{*_{e}}+0\right)$, which is given as a function of the aspect ratio [7] as follows:

$$
f_{T}(\delta)=1-(1-\delta)^{2}\left(1-\delta^{2}\right)^{-1 / 2}\left(1+1.46 \delta^{1 / 2}\right)^{-1} .
$$

$y$ For $v_{\star_{e}} \rightarrow 0$, Eq. (4) agrees with the value for the banana regime conductivity of an arbitrary aspect ratio plasma [6]. When $v_{*_{e}}$ is finite and $\delta \ll 1, E q$. (4) reproduces the results of Ref. [5].

To complete the conductivity formula Eq. (4), the expresion for the Spitzer function $F_{S}$, obtained in Ref. [8] by a three-term Sonine polynomial expansion in $\mathrm{x}_{e}^{2}$, was used:

$$
F_{S}\left(\bar{z}, x_{e}\right)=\Lambda_{E}(\bar{z})-\Lambda_{T}(\bar{z}) L_{1}\left(x_{e}^{2}\right)+\frac{8}{15}\left(\bar{z}^{-1}-\Lambda_{E}+\frac{3}{2} \Lambda_{T}\right) L_{2}\left(x_{e}^{2}\right)
$$

where

$$
\Lambda_{E}(\overline{\mathrm{z}})=\frac{3.40}{\overline{\mathrm{z}}}\left(\frac{1.13+\overline{\mathrm{z}}}{2.67+\overline{\mathrm{z}}}\right)
$$




$$
\begin{aligned}
& \Lambda_{T}(\bar{z})=2.06\left(\frac{1.38+\bar{z}}{3.23+4.68 \bar{z}^{2}+\bar{z}}\right) \\
& L_{1}\left(x_{e}^{2}\right)=\frac{5}{2}-x_{e}^{2} \\
& L_{2}\left(x_{e}^{2}\right)=\frac{35}{8}-\frac{7}{2} x_{e}^{2}+\frac{1}{2} x_{e}^{4}
\end{aligned}
$$

II. COMPARISON WITH PREVIOUS CALCULATIONS

The present conductivity expression, Eq. (4), is plotted in Fig. 1 for each of two values of the effective charge $\overline{\mathrm{Z}}=1,4$ and for small and finite values of $\delta=0.05$ and $\delta=0.2$. For comparison, the results of Ref. [3] and Ref. [4] are also plotted. For $\delta=0.05$, the present curve agrees well with the numerical results of Ref. [3], whereas for $\delta=0.2$, finite aspect ratio corrections produce a significant discrepancy at small to intermediate values of $v_{*_{e}}$. The failure of the formula of Ref. [4] to scale correctly with increasing $\bar{z}$, noted previously, is only marginally discernable for the relatively small values of $\bar{z}$ depicted in the figure. 
III. APPROXIMATE ANALYTIC CONDUCTIVITY FORMULA i

The expression Eq. (4) for the conductivity suggests an analytic approximation of the form

$$
\sigma_{\|} / \sigma_{0}=\Lambda_{E}(\bar{z})\left(1-\frac{f_{T}}{1+\xi \nu_{\star_{e}}}\right)\left(1-\frac{c_{R}(\bar{z}) f_{T}}{1+\xi \nu_{\star_{e}}}\right)
$$

where

$$
\sigma_{R}(\bar{z}) \equiv \frac{8}{3 \sqrt{\pi}} \int_{0}^{\infty} x_{e}^{4} e^{-x_{e}^{2}} d x_{e} F_{s}\left(\nu_{D}^{e} \tau_{e} F_{s}-1\right) / \Lambda_{E}(\bar{z})
$$

is the conductivity reduction due to electron-electron collisions which vanishes as $1 / \bar{z}+0 . \quad c_{R}$ was computed numerically and is accurately fit by the formula

$$
C_{R}(\bar{z})=\frac{0.56}{\bar{z}}\left(\frac{3.0-\bar{z}}{3.0+\bar{z}}\right)
$$

Note that $c_{R}$ is nearly zero for $\bar{z}>3$, thus decreasing more rapidly than indicated by the dependence $c_{R}(\bar{z})=c_{R}(l) / \bar{z}$ previously assumed [3]. The fact that $C_{R}$ is small and negative for $\overline{\mathrm{Z}}>3$ is probably due to the approximate nature of $\mathrm{F}_{\mathbf{s}}$ used here. Physically, collisions between trapped and circulating electrons should decrease $\sigma_{\|}$, implying positive-definite $c_{R^{*}}$

The parameter $\xi$ was determined by a least squares fit of Eqs. (4) and (10), for fixed $\delta$ and $\bar{z}$, over the range $10^{-2}<v_{*_{e}}<10^{2}$. The extremizing value of $\xi$, for the range of tokamak parameters $0 \leq \delta \leq 0.4,1 \leq \bar{z} \leq 20$, was found to be 
(almost) independent of $\delta$ and given by the relation

$$
\xi(z)=0.58+0.20 \bar{z} .
$$

[Actually, there is a small $\delta$ dependence of $\xi$, but since $(\delta / \xi)|\mathrm{d} \xi / \mathrm{d} \delta| \leqslant 0.08$, it has a negligible effect on the conductivity given in Eq. (10).]

The approximate conductivity formula Eq. (10), with $\Lambda_{E}(z)$ defined in Eq. (9b), $f_{T}(\delta)$ in Eq. (8), $c_{R}(z)$ in Eq. (llb), and $\xi(z)$ in Eq. (12), yields a maximum error (for all values of $\nu_{*_{e}}$ and $\bar{z}$ in the range studied) which increases from 4.38 for $\delta=0.1$ to $5.5 \%$ for $\delta=0.3$ to a peak of $7.3 \%$ for $\delta=0.4$. To illustrate the accuracy of the present approximation, Fig. 2 compares the two conductivity relations, Eqs. (4) and (10), for $\bar{Z}=1$ (the value of effective charge for which the maximum error occurs for fixed $\delta$ ) and $\bar{z}=4$, and the two values $\delta=0.1$ and $\delta=0.3$.

\section{ACKNOWLEDGMENT}

This work was supported by United States, Energy Research and Development Administration Contract E(11-1)-3073. 


\section{REFERENCES}

[1] BRETZ, N., DIMOCK, D., HINNOV, E., and JOHNSON, D., Bull. Am. Phys. Soc. 21 (1976) 1159.

[2] HINTON, F.I., ROSENBLUTH, M.N., Phys. Fluids 16 (1973) 836 .

[3] HINTON, F.L., HAZELTINE, R.D., Rev. Mod. Phys. 48 (1976) 239 .

[4] RUTHERFORD, P.H., DÜCHS, D.F., Princeton Plasma Phys. Labor. 1272 (1976).

[5] HIRSHMAN; S.P., SIGMAR, D.J., Phys. Fluids 20 (1977, in press).

[6] HAZELTINE, R.D., HINTON, F.L., and ROSENBLUTH, M.N., Phys. Fluids 16 (1973) 1645.

[7] HIRSHMAN, S.P., SIGMAR, D.J., and CLARKE, J.F., PhYs. Fluids 19 (1976) 656 .

[8] BRAGINSKII, S.I., Zh. Eksp. Teor. Fiz $\underline{33}$ (1957) 459 [English translation - Sov. Phys. JETP 6 (1958) 358]. 

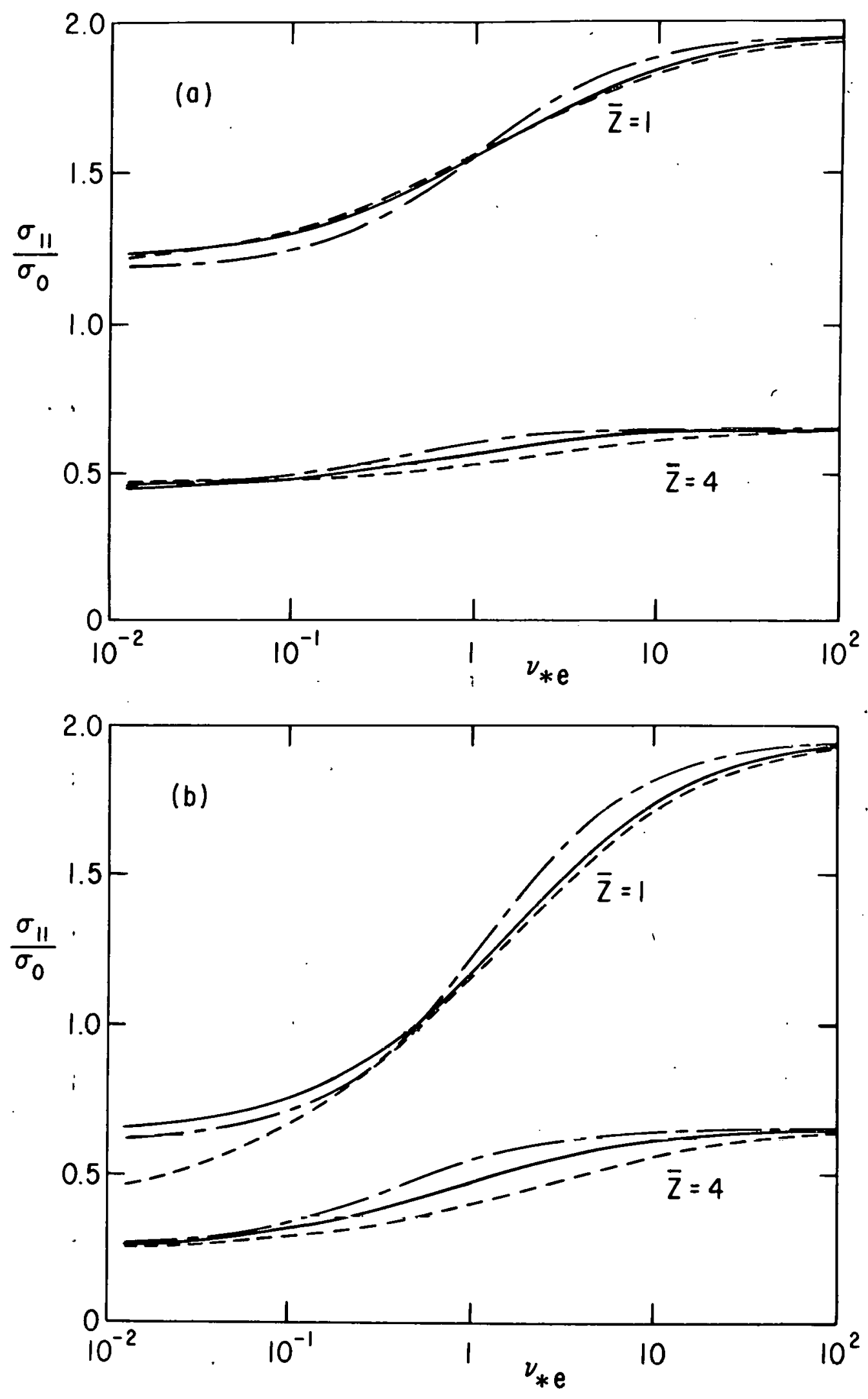

7720.24

Fig. 1: Values of the conductivity for $\bar{z}=1,4$ vs. $\nu_{* e}$ computed from Eq. (4) (solid), Ref. [3] (dashed), and Ref. [4] (dashed-dotted), for (A) $\delta=0.05$ and (B) $\delta=0.2$. 

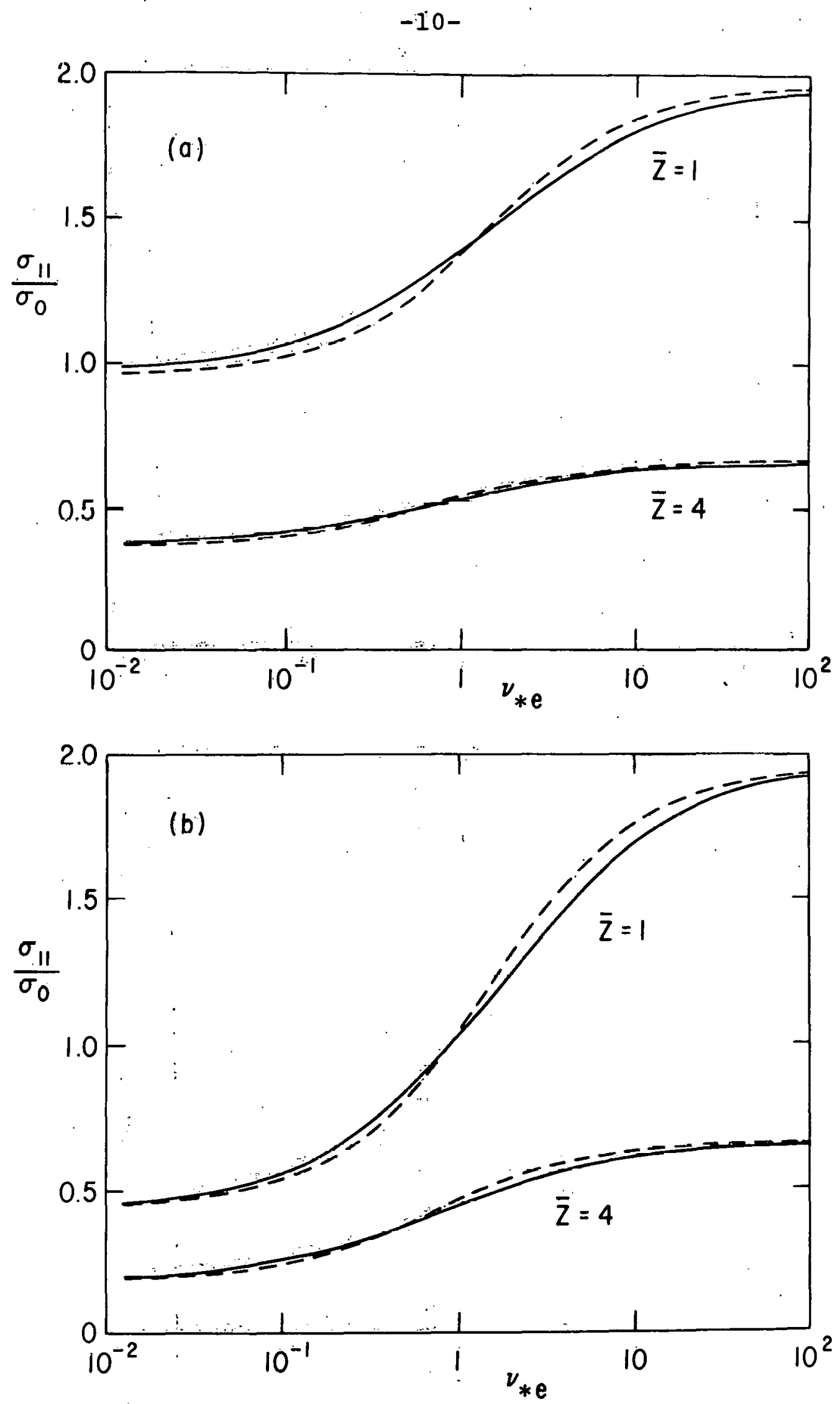

772023

Fig. 2: Values of the conductivity for $\bar{z}=1,4$ vs. $v_{*_{e}}$ computed from Eq. (4) (solid), and Eq. (10) (dashed), for (A) $\delta=0.1$ and (B) $\delta=0.3$ 